\title{
Adoption of a multi-criteria approach for the selection of operational measures in a maritime environment
}

\author{
Desmond Ighravwe ${ }^{a^{*}}$, Daniel AIkhuele ${ }^{a}$, Ojo Sunday Isaac Fayomi ${ }^{\text {b }}$ and Anayo Dike Anayo \\ Dike Basil $^{\mathrm{a}}$
}

${ }^{a}$ Bells University of Technology College of Engineering, Nigeria

${ }^{b}$ Covenant University College of Engineering, Nigeria

\section{H R O N I C L E}

Article history:

Received: December 31, 2020

Received in revised format: May 1,2021

Accepted: July 10, 2021

Available online:

July 11, 2021

Keywords:

Operations

Multi-criteria

Maritime industry

VIKOR

Decision-making

\section{A B S T R A C T}

\begin{abstract}
In recent times, there have been developments in the maritime industry that underscore the need to optimise operations to yield maximum productivity. Apart from this, stakeholders in this industry have also advocated improvements in seaport operations' critical areas. However, there is no known study in which the relationship between performance criteria and seaport operation measures is investigated. This study proposes a framework for selecting operation measures for the maritime industry. It uses stakeholders' expectations for operational criteria and fuzzy logic to design the framework. Nine criteria were considered in the framework, while Fuzzy VIKOR (VIsekriterijumska optimizacija I KOmpromisno Resenje) and fuzzy Shannon entropy were incorporated into it. The framework's applicability was tested using information that was obtained from Tin can port, Lagos, Nigeria. During this process, hinterland traffic diversion (A1), congestion pricing (A2), off-dock container yards (A3), Fast rail shuttles (A4), expanded rail connections (A5) were considered as alternatives for seaport operational measures. When the developed framework was used to analyse the collected information from Tin Can port, Lagos, Nigeria, the fuzzy VIKOR index ranked the alternatives as $A_{1} » A_{2} \gg A_{3} » A_{5} \gg A_{4}$. Therefore, this study's insights show that mathematical models can be used to make informed seaports decisions.
\end{abstract}

\section{Introduction}

Today's industries are redefining and refining their operations amidst the current COVID-19 pandemic. The maritime industry is not excluded from this redefining and refining process because of the level of activities that takes place in seaports. Some of these activities are transportation, berth allocation and crane assignment, capital management, risk management, and power mobilisation (Guenther et al., 2006; Vale, Ribeiro, and Branco, 2017). Human engagement in these activities is seaport-dependent. These make scholars adopt different approaches as solution methods for the same type of problems in seaports. Before an approach is adopted, a problem is defined using established literature. This is to improve the acceptability of a proposed approach among scholars and practitioners in the maritime industry. Scholars have eased this process by reporting reviews on the state-of-the-art in the maritime sector (Dirk \& Stahlbock, 2004; Wright et al., 2013; Yang et al., 2014). These reviews have helped scholars and practitioners to proffer innovative solutions to problems in the maritime

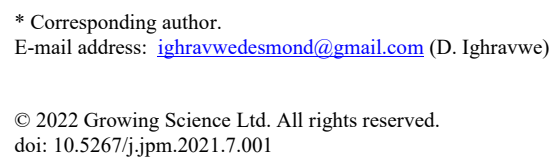


industry. For instance, Fang et al. (2019) presented an overview of that contains information about making maritime transportation to be green. (Gong and Liu, 2020) discussed a solution method for dealing with the issue of disasters and labour strikes in dry ports.

Most of the studies are presented to improve maritime policies. Such policies are meant to make seaports efficient and effective. Hence, more vital information can be obtained from studies that provide policy-makers input when solutions are generated for specific seaport problems. To achieve this, scholars have recommended multi-criteria decision-making (MCDM) methods to improve the robustness of policy-makers' decisions in the maritime industry. In short, some of these scholars have opined at least techno-economic, socio-environmental, or both should be included in decision support systems for the maritime industry. To support policy-makers with practical information, we designed a framework that uses technoeconomic and social criteria to improve seaport operation measures' selection process. In the framework, fuzzy logic is extended to the evaluation process. This makes it possible to capture the vagueness and uncertainty in decision-makers opinion during the evaluation of the measures. Finally, the unique properties of fuzzy VIKOR (VIsekriterijumska optimizacija I KOmpromisno Resenje) and Combined Compromise Solution (COCOSO) are used to justify why multi-criteria tools should be used in the maritime industry.

Globally, studies have shown that stakeholders are reviewing seaport operations with the sole aim of improving on existing infrastructure (Dirk and Stahlbock, 2004; Wright et al., 2013). For instance, they seek to improve the equilibrium between business owners and government regulatory agencies in seaports. This improvement aims to address some of the challenges that port users faced when they go about their lawful activities. Speed-up operations delivering processes and productivity enhancement are among the issues that need to be improved, especially as stakeholders desire effective and efficient seaports (Yang et al., 2014). On the one hand, governments in developed countries invest huge capital research institutes with a mandate of proffering solutions to the problems mentioned above.

On the other hand, governments in developing countries, such as Nigeria, are yet to design sustainable roadmaps for these problems. Their excuse has always been lacks of capital, corruption, and lack of willpower - to mention a few. Hence, seaports operation measures are selected based on rule-of-thumb instead of a scientific approach. This approach of this measure selection has further worsened seaports challenges in developing countries.

Currently, hinterland traffic diversion, congestion pricing, and off-dock container yards are among these measures for seaport operation improvement (Meersman et al., 2012). However, scholars and practitioners have failed to connect these measures with existing criteria for benchmarking seaport operations. This failure can be traced to limited studies on multicriteria decision-making tools in the maritime industry, especially in developing countries. This study proposes a novel framework for these measures' evaluation to improve the use of operational measures. It identifies criteria that are important to make an informed decision on operational measures selection. Also, it determines these criteria importance to know the criteria that influence a decision on operation measures selection. This study also uses a fuzzy VIKOR method to provide a scientific basis for selecting a seaport's particular operation measure. Finally, this study introduced the use of COCOSO for operation measures selection.

\section{Literature Review}

The amounts of activities going on in seaports make their operations complicated and convoluted. Hence, scholars are restricted to use different mathematical approaches to proffer solutions to specific seaports operational problems. Some of the issues identified in seaports are berth and quay crane allocation problem (Na and Zhihong, 2009); load planning problem (Ambrosino et al., 2011); berth planning problem (Song et al., 2012); container stacking problem (Moussi et al., 2015); seaport productivity (Ighravwe \& Anyaeche, 2019), efficient cargo operation schedule problem (Vasileva \& Kiyaev, 2018); traffic Scheduling Problem (Li \& Jia, 2019); and transhipment operations problem (Yan et al., 2020). The problems mentioned above have been solved using different techniques, which are not limited to simulation, optimisation, and artificial intelligence methods. Some scholars have combined two or more methods when addressing these problems (Iris et al., 2015; Song et al., 2012; Wang et al., 2019). Apart from combining solution methods, some scholars have solved two or more problems simultaneously (Iris et al., 2015; Kasm et al., 2019).

Berth planning problem has been addressed from various perspectives. For instance, Ighravwe and Anyaeche (2019) used an artificial neural network approach to measure seaport productivity and effectiveness. In another study, Song et al. (2012) proposed a mixed-integer linear model for berth planning problem. They combined genetic algorithm and a branch-andbound method to generate an optimal solution for this planning problem. Wang et al. (2019) developed a model for solving a berth allocation problem under a dynamic condition. Their model was developed based on the unique attributes of mathematical programming and a levy flight algorithm. This algorithm performance was compared with particle swarm optimisation (PSO) algorithm. The comparison of these algorithms, i.e. levy flight and PSO algorithms, showed that the levy flight algorithm-generated better results than the levy flight the PSO algorithm.

Iris et al. (2015) formulated a berth planning problem as an integrated problem. They achieved this by integrating a quay crane assignment and berth planning problems. The integrated problem's complexity made them use an integer programming model and set partitioning column reduction to solve it. Kasm et al. (2019) were able to concurrently generate prom- 
ising results for quay crane assignment, berth planning, and scheduling problems in seaports. They used a binary optimisation modelling approach to optimise vessel operation. Special consideration was given the arrival and processing time of vessels that dock in a seaport. Container stacking problem is among the prevailing problems that most seaports worldwide are battling with because of its effect on seaports' overall performance (Moussi et al., 2015).

Given that scholars have recognised the importance of this problem, most of them depend on optimisation models and metaheuristics to solve this problem. For instance, Euchi et al. (2016) discussed the importance of using an art colony algorithm to solve this problem when formulated as a binary optimisation problem. Their interest was to ensure that the containers' storage location is optimally positioned because of space utilisation in seaports.

Moussi et al. (2015) used a memetic algorithm to solve a container stacking problem. This algorithm hybridised ant colony algorithm and simulated annealing. To make their solution practicable, they considered types of stalks and containers and containers department time. Also, consideration was given to the distance between a stack and a vessel. With these considerations, they were able to optimise containers unloading time. Apart from using an optimisation model to solve the container stacking problem, the multi-agent approach has been reported as a viable solution method for this problem. This approach was used by Rekik et al. (2017) to generate a solution for dangerous containers in a seaport. Also, they used this solution method to identify the most suitable locations for this category of containers. Rekik and Elkosantini (2019) extended this method's discussion to a remote system for container stacking. This was achieved by incorporating fuzzy logic and multi-agent as a solution for dealing with this stacking problem. With this approach, they designed a system improved container storage strategy.

Cargo scheduling in seaports serves as one means of ensuring smooth operation in seaports. Hence, decision-makers often evaluate their scheduling strategies for cargo. These strategies are by-products from scholarly publications that are reported in academic and non-academic literature. One such publication was published by (Vasileva and Kiyaev, 2018). In their work, a multi-agent approach was used to integrate different parameters: crane and fuel tankers, which affect cargo schedule. Their study outcomes observed that the multi-agent modelling approach could improve the efficiency of cargo schedule. To improve the discussion on this scheduling problem, Vasileva and Kiyaev (2018a) integrated multi-agent and genetic algorithm as a solution method for cargo schedule. Their proposed approach for this problem addresses the issue of loading and unloading in seaports. On the part of Agarwal and Ergun (2008), they believe that modelling this problem requires transhipment consideration. Hence, they were able to model this problem as a mixed-integer problem. However, this modelling approach makes the problem to be an NP-hard problem.

To solve the above-mentioned NP-hard problem, Agarwal and Ergun (2008) combined different heuristics: greedy heuristic, column generation-based algorithm, and a Benders decomposition algorithm. Technically, this problem deals with the scheduling of vessels and other means of transportation in a seaport. Hence, researchers are forced to consider the prevailing characteristics of different routes that enter a seaport. To effectively solve this problem, there is a need to consider handling capacity, storage cost, and yard capacity (Yan et al., 2020). Solving this problem helps to improve the reliability of shipping (Mi, 2016). Recently, Yan et al. (2020) considered the relationship between vessels and trains. Their study was motivated by the need to minimise the operational cost in a seaport. A mixed-integer programming approach was used to generate an optimal solution for service and unloading time to achieve this objective. In another recent study, Aguilar-Chinea et al. (2019) proposed a decision tree algorithm for this problem robustness prediction. In their work, they used unloading time, vehicles, and cranes attribute to predict transhipment robustness.

Yan et al. (2020) discussed the possibility of optimising the storage time and dwell time of inbound containers in a seaport. Using an integer programming modelling and backtracking strategy, they could generate optimal storage time values during transhipment operations. On the part of Mi (2016), they suggested a mixed-integer modelling approach for the transhipment problem. They believe that the uncertainty inherent in this problem needs to be modelled and used to improve transhipment in the shipping industry, especially as it affects liner shipping service networks.

\section{Methodology}

The methodology used to achieve the objective of this study is discussed in this section. Figure 1 shows the proposed framework for seaports operation measures evaluation. This framework integrates the unique properties of fuzzy Shannon entropy and fuzzy VIKOR methods. In the framework, the fuzzy Shannon entropy method is used to determine the importance of evaluation criteria. Ranks for alternatives are generated using the fuzzy VIKOR method. In the framework, experts' opinions generate information for the proposed model evaluation and validation. Here, validation is carried out using a fuzzy COCOSO method. This validation is meant for the fuzzy VIKOR results.

\subsection{Fuzzy Shannon Entropy Method}

Technically, this Shannon entropy method has enjoyed wide application in decision science. Because of its ease of application, fuzzy logic has been incorporated into its framework. This makes it possible for it to be used to analyse criteria that are expressed in linguistic terms and under a condition of uncertainty and vagueness (Shemshadi et al., 2011; Wang \&Lee, 2009). This method implementation is based on experts' opinions (Eq. (2)). 


$$
D=\left[\begin{array}{lcc}
w_{i j 1}^{1} & \ddots & w_{i j 1}^{n} \\
w_{i j 2}^{1} & \ddots & w_{i j 2}^{n} \\
w_{i j 3}^{1} & \ddots & w_{i j 3}^{n} \\
\vdots & \ddots & \vdots \\
w_{i j m}^{1} & \ddots & w_{i j m}^{n}
\end{array}\right]
$$

Trapezoidal fuzzy numbers are used to combined the experts' opinions to analyse the criteria further (Fig. 2). This process involves converting these fuzzy numbers to crisp values (Shemshadi et al., 2011). Eq. (3) is used for this conversion process.

$$
w_{i j}=\frac{w_{i j}^{4} w_{i j}^{3}+1 / 3\left(w_{i j}^{4}-w_{i j}^{3}\right)^{2}-w_{i j}^{2} w_{i j}^{1}-1 / 3\left(w_{i j}^{2}-w_{i j}^{1}\right)^{2}}{w_{i j}^{4}+w_{i j}^{3}-w_{i j}^{2}-w_{i j}^{1}}
$$

After the conversion process, Eq. (4) is used to normalise the criteria. This process is proceeded by the determination of entropy measures for the criteria (Eq. (5)).

$$
\bar{w}_{i j}=\frac{w_{i j}}{\sum_{j \in n} w_{i j}}
$$

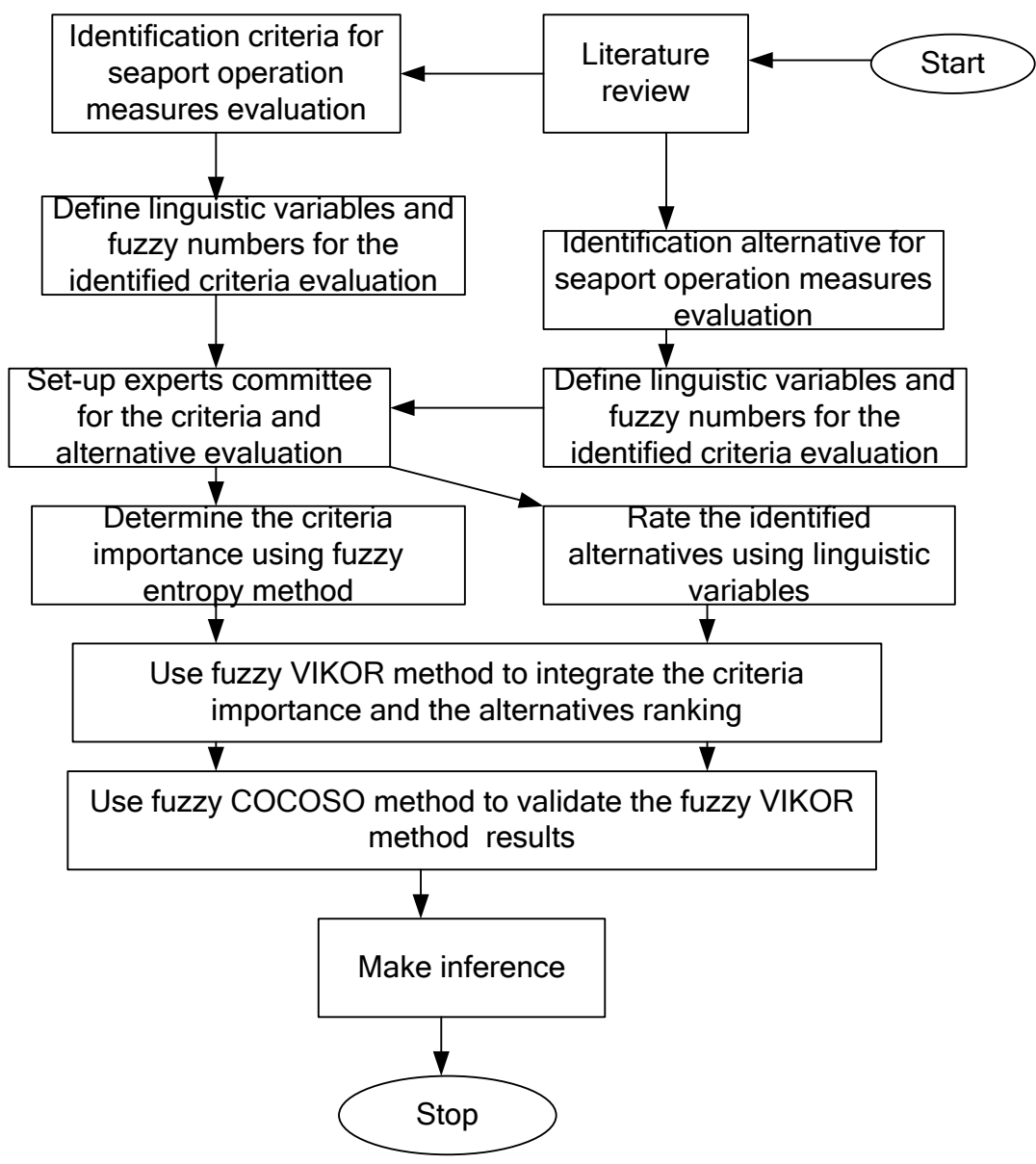

Fig. 1. Proposed framework for seaports operation measures evaluation 


$$
e_{j}=-\frac{1}{\ln (m)} \sum_{i \in m} \bar{w}_{i j} \ln \bar{w}_{i j}
$$

Based on the entropy measures, each criteria divergence value is determined using Eq. (6). This process is proceeded by the criteria importance determination (Eq. (7)).

$$
\begin{aligned}
& d_{j}=1-e_{j} \\
& w_{j}=\frac{d_{j}}{\sum_{j \in n} d_{j}}
\end{aligned}
$$

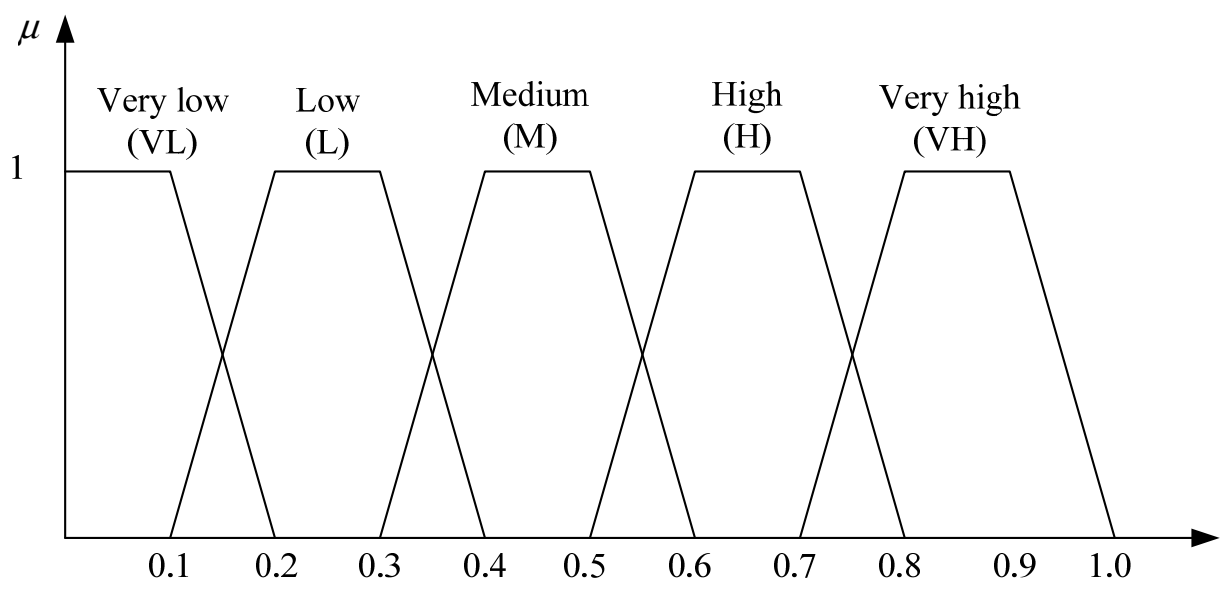

Fig. 2. Fuzzy trapezoidal numbers

\subsection{VIKOR method}

This multi-criteria method uses the concept of a compromise solution to rank alternatives during a decision-making process. To achieve this, it computes surplus, regret and VIKOR values for an alternative based on criteria. The steps below highlight the various processes that are considered before these values can be computed.

\section{Step 1: Experts' opinion aggregation}

This step outlines the approach that is used to aggregate experts' opinions. Technically, the aggregation method depends on the type of fuzzy numbers used to convert linguistic variables to a fuzzy number. For example, Eq. (8) to Eq. (11) give the mathematical expressions for trapezoidal fuzzy numbers (Shemshadi et al., 2011).

$$
\begin{aligned}
& x_{i j}^{1}=\min _{e}\left\{x_{i j e}^{1}\right\} \\
& x_{i j}^{2}=\frac{1}{E} \sum_{e \in E} x_{i j e}^{2} \\
& x_{i j}^{3}=\frac{1}{E} \sum_{e \in E} x_{i j e}^{3} \\
& x_{i j}^{4}=\max _{e}\left\{x_{i j e}^{4}\right\}
\end{aligned}
$$

\section{Step 2: Normalisation process}

Normalisation helps to reduce the size of data. During this process, criteria are divided into benefit and cost-based. First, the maximum and minimum values for the benefit and cost-based criteria are determined using Eq. (12) and Eq. (13).

$$
x_{i j}=\max _{C_{j} \in B}\left\{x_{i j}^{4}\right\}
$$




$$
x_{i j}=\min _{C_{j} \in C}\left\{x_{i j}^{1}\right\}
$$

Based on the maximum, the benefit-based criteria are normalised using Eq. (14), while Eq. (15) is used for cost-based criteria normalisation.

$$
\begin{aligned}
& u_{i j}=\frac{x_{i j}^{1}}{x_{i j}^{+}}, \frac{x_{i j}^{2}}{x_{i j}^{+}}, \frac{x_{i j}^{3}}{x_{i j}^{+}}, \frac{x_{i j}^{4}}{x_{i j}^{+}} \quad c_{j} \in B \\
& u_{i j}=\frac{x_{i j}^{1}}{x_{i j}^{-}}, \frac{x_{i j}^{2}}{x_{i j}^{-}}, \frac{x_{i j}^{3}}{x_{i j}^{-}}, \frac{x_{i j}^{4}}{x_{i j}^{-}} \quad c_{j} \in C
\end{aligned}
$$

\section{Step 3: Overall performance evaluation}

The overall performance of criteria is determined by converting the normalised fuzzy values to crisp values. In this study, Equation (3) is used for this conversion process. Based on the converted values, Eq. (16) and Eq. (17) is used to determine the maximum and minimum overall performance, respectively.

$$
\begin{aligned}
& f_{j}^{+}=\max _{j \in n}\left\{u_{i j} w_{j}\right\} \\
& f_{j}^{-}=\min _{j \in n}\left\{u_{i j} w_{j}\right\}
\end{aligned}
$$

\section{Step 4: Surplus and Regret values evaluation}

Using the maximum overall values, Eq. (18) generated the alternatives' surplus values. Similarly, the minimum overall values are used to determine an alternative's regret value (Eq. (19)).

$$
\begin{aligned}
& S_{i}=\sum_{j \in n} \frac{f_{j}^{+}-u_{i j} w_{j}}{f_{j}^{+}-f_{j}^{-}} \\
& R_{i}=\max _{i} \frac{f_{j}^{+}-u_{i j} w_{j}}{f_{j}^{+}-f_{j}^{-}}
\end{aligned}
$$

\section{Step 5: VIKOR value determination}

The relationship between the surplus and regret values is used to determine an alternative VIKOR value. However, a controlling coefficient is introduced to assess the contribution of these values during VIKOR value evaluation. Also, this coefficient allows stakeholders to simulate different outcomes from experts' opinions. Before this can be achieved, the maximum and minimum surplus and regret for the evaluation process must be determined using Eq. (20) to Eq. (23), respectively.

$$
\begin{aligned}
& S_{i}^{+}=\max _{i \in m}\left\{S_{i}\right\} \\
& S_{i}^{-}=\min _{i \in m}\left\{S_{i}\right\} \\
& R_{i}^{+}=\max _{i \in m}\left\{R_{i}\right\} \\
& R_{i}^{-}=\min _{i \in m}\left\{R_{i}\right\}
\end{aligned}
$$

Based on the expressed presented in Eq. (20) to Eq. (23), Eq. (24) gives the VIKOR value for a criterion.

$$
Q_{i}=v \frac{S_{i}-S_{i}^{-}}{S_{i}^{+}-S_{i}^{-}}+(1-v) \frac{R_{i}-R_{i}^{-}}{R_{i}^{+}-R_{i}^{-}}
$$

Having presented the steps for alternatives' surplus, regret and VIKOR values evaluation, the remaining paragraphs in this section explain how to use these values to make a decision. First, the surplus values are used to decide based on the higher, the better. Conversely, the regret values are used to decide based on the lower, the better. For the VIKOR values, a decision is made based on the higher, the better.

The following conditions are considered to determine the optimality of a decision-making process: 


\section{a. Condition 1: Acceptable advantage}

This condition states that for a solution to be optimal, $Q\left(A^{2}-A^{1}\right) \geq D R$

$$
D R=\frac{1}{i-1}
$$

\section{b. Condition 2: Acceptable stability}

Alternative $\mathrm{A}^{(1)}$ must also be the best ranked by $\mathrm{S}$ or/and $\mathrm{R}$. This compromise solution is stable within a decision-making process.

\subsection{COCOSO method}

COCOSO method is among the newly developed multi-criteria tools that have been used to generate results for different multi-criteria decision-making problems. This method is a novel multi-criteria method that depends on three sequences when analysing multi-criteria problems. Technically, it combines an exponentially weighted product model and a simple additive weighting method during alternatives ranking. The evaluation process starts with the formulation of a decision matrix (Equation 26). The matrix's entries are presented as fuzzy values.

$$
X=\left|\tilde{x}_{i j}\right|_{m \times n}
$$

Since this matrix element is fuzzy, a fuzzy normalisation approach is used to normalise these elements. Generation of the normalised values for the alternatives proceeds this conversion process. However, consideration is given to benefit and nonbenefit criteria. Eq. (27) is considered to normalise benefit criteria, while Eq. (28) is used to normalise non-benefit criteria.

$$
\begin{array}{ll}
n_{i j}=\frac{x_{i j}}{\max _{i}\left\{x_{i j}\right\}} & j \in C_{b} \\
n_{i j}=\frac{\min _{i}\left\{x_{i j}\right\}}{x_{i j}} & j \in C_{c}
\end{array}
$$

After the normalisation, crisp values are generated for the alternatives using Eq. (11). Based on the normalised values, the power of the weighted compatibility sequence for the alternatives is generated (Eq. (28)). Before the normalised values are used for further analysis, they are converted to crisp values. This normalised decision matrix generates the sum of the weighted compatibility sequences for the alternatives (Eq. (29)).

$$
\begin{aligned}
& G_{i}=\sum_{j=1}^{n}\left(x_{i j}\right)^{w_{j}} \\
& H_{i}=\sum_{j=1}^{n}\left(x_{i j} w_{j}\right)
\end{aligned}
$$

These sequences are used to generate appraisal scores for the evaluation process (Eq. (30) to Eq. (32)). A control coefficient is used to control the contributions of the sequences during the evaluation process. Another benefit of this coefficient is that it allows decision-makers to simulate different outcomes for the evaluation process.

$$
\begin{aligned}
S_{i}^{\alpha} & =\frac{G_{i}+H_{i}}{\sum_{i=1}^{m}\left(G_{i}+H_{i}\right)} \\
S_{i}^{\beta} & =\frac{G_{i}}{\min \left(G_{i}\right)}+\frac{H_{i}}{\min \left(H_{i}\right)} \\
S_{i}^{\gamma} & =\frac{\lambda H_{i}+(1-\lambda) G_{i}}{\lambda \max _{i}\left(H_{i}\right)+(1-\lambda) \max _{i} G_{i}}
\end{aligned}
$$


These scores are aggregated to rank an alternative. The best alternative becomes the alternative with the highest score, while the worst alternative is the alternative with the lowest score (Ulutaş et al., 2020).

$$
S_{i}=\left(S_{i}^{\alpha} S_{i}^{\beta} S_{i}^{\gamma}\right)^{1 / 3}+\frac{1}{3}\left(S_{i}^{\alpha} S_{i}^{\beta} S_{i}^{\gamma}\right)
$$

\section{Case Study}

In this study, information from Tin can port in Lagos, Nigeria, is used as a case study for the proposed framework evaluation and validation. During the framework evaluation, nine criteria and five alternatives were considered to determine the framework's sufficiency to determine the best and worst alternatives. A well-structured questionnaire is used to collect information from four experts. In the questionnaire, two sections were created. The first section contains information on the criteria importance, while the second section contains information on the alternatives' ranking.

Table 1 shows the criteria used to determine the best and worst alternatives for the maritime industry's operation measures selection. Practically, these criteria can be classified as techno-economic and social criteria. They can capture the complexity in operation measures analysis in seaports. Table 2 presents the linguistic variables for their importance evaluation. This study used trapezoidal fuzzy numbers to convert linguistic values into crisp values.

Table 1

Evaluation criteria

\begin{tabular}{lll}
\hline Criterion & Criterion & Criterion \\
\hline C1: Efficiency & C4: Safety & C7: Skill availability \\
C2: Speed-up operations delivering processes & C5: Effectiveness & C8: Acceptability \\
C3: Productivity enhancement & C6: Reliability & C9: Customers' satisfaction \\
\hline
\end{tabular}

Table 2

Linguistic terms and corresponding fuzzy numbers for each criterion

\begin{tabular}{lc}
\hline Linguistic variables & Fuzzy numbers \\
\hline Highly unimportant & $(0.1,0.2,0.3,0.4)$ \\
Unimportant & $(0.3,0.4,0.5,0.6)$ \\
Moderately important & $(0.5,0.6,0.7,0.8)$ \\
Highly important & $(0.7,0.8,0.9,1.0)$ \\
Extremely important & $(0.9,1.0,1.0,1.0)$ \\
\hline
\end{tabular}

Table 3 presents the experts' rating of the criteria importance. These linguistic variables conversion to fuzzy values is based on the information in Table 2. Based on the converted values (Table 4), the Shannon method generated the weights in Table 5 .

Table 3

Ratings of criteria assessed by maritime decision-makers

\begin{tabular}{|c|c|c|c|}
\hline Criterion & DM1 & DM2 & DM3 \\
\hline $\mathrm{C} 1$ & EI & $\mathrm{M}$ & EI \\
\hline $\mathrm{C} 2$ & EI & EI & EI \\
\hline $\mathrm{C} 3$ & HI & EI & EI \\
\hline $\mathrm{C} 4$ & HI & $\mathrm{H}$ & M \\
\hline $\mathrm{C} 5$ & HI & EI & EI \\
\hline C6 & HI & $\mathrm{H}$ & EI \\
\hline $\mathrm{C} 7$ & HI & EI & $\mathrm{H}$ \\
\hline $\mathrm{C} 8$ & HI & M & HI \\
\hline C9 & EI & EI & EI \\
\hline
\end{tabular}

Table 4

Rating of the criteria using fuzzy trapezoidal numbers

\begin{tabular}{|c|c|c|c|c|c|c|c|c|c|c|c|c|}
\hline \multicolumn{5}{|c|}{ DM1 } & \multicolumn{4}{|c|}{ DM2 } & \multicolumn{3}{|c|}{ DM3 } & \\
\hline $\mathrm{C} 1$ & 0.8 & 0.9 & 1 & 1 & 0.5 & 0.6 & 0.7 & 0.8 & 0.8 & 0.9 & 1 & 1 \\
\hline $\mathrm{C} 2$ & 0.8 & 0.9 & 1 & 1 & 0.8 & 0.9 & 1 & 1 & 0.8 & 0.9 & 1 & 1 \\
\hline C3 & 0.7 & 0.8 & 0.9 & 1 & 0.8 & 0.9 & 1 & 1 & 0.8 & 0.9 & 1 & 1 \\
\hline $\mathrm{C} 4$ & 0.7 & 0.8 & 0.9 & 1 & 0.8 & 0.9 & 1 & 1 & 0.5 & 0.6 & 0.7 & 0.8 \\
\hline $\mathrm{C} 5$ & 0.7 & 0.8 & 0.9 & 1 & 0.8 & 0.9 & 1 & 1 & 0.8 & 0.9 & 1 & 1 \\
\hline C6 & 0.7 & 0.8 & 0.9 & 1 & 0.7 & 0.8 & 0.9 & 1 & 0.8 & 0.9 & 1 & 1 \\
\hline C7 & 0.7 & 0.8 & 0.9 & 1 & 0.8 & 0.9 & 1 & 1 & 0.7 & 0.8 & 0.9 & 1 \\
\hline $\mathrm{C} 8$ & 0.7 & 0.8 & 0.9 & 1 & 0.5 & 0.6 & 0.7 & 0.8 & 0.8 & 0.9 & 1 & 1 \\
\hline $\mathrm{C} 9$ & 0.8 & 0.9 & 1 & 1 & 0.8 & 0.9 & 1 & 1 & 0.8 & 0.9 & 1 & 1 \\
\hline
\end{tabular}


The information in Table 5 shows that the most important criteria are $\mathrm{C} 1, \mathrm{C} 4$, and $\mathrm{C} 8$. The least important criteria are $\mathrm{C} 2$ and $\mathrm{C} 9$. The importance of $\mathrm{C} 3, \mathrm{C} 5, \mathrm{C} 6$, and $\mathrm{C} 7$ are the same.

Table 5

Importance of the evaluation criteria

\begin{tabular}{lccccc}
\hline Criterion & Importance & Criterion & Importance & Criterion & Importance \\
\hline C1 & 0.112 & C4 & 0.112 & 0.111 & C7 \\
C2 & 0.110 & C5 & 0.111 & C8 & 0.112 \\
C3 & 0.111 & C6 & 0.111 & C9 & 0.110 \\
\hline
\end{tabular}

Table 6 presents the available operation measures for the seaport. These criteria were selected based on suggestions from experts in the maritime industry. During the evaluation process, the experts used the information in Table 7 to rate these measures.

Table 6

Alternatives for the evaluation process

\begin{tabular}{l}
\hline Alternative \\
\hline Hinterland traffic diversion (A1) \\
Congestion pricing (A2) \\
Off-dock container yards (A3) \\
Fast rail shuttles (A4) \\
Expanded rail connections (A5) \\
\hline
\end{tabular}

Table 7

Linguistic terms and corresponding fuzzy numbers for each measure

\begin{tabular}{lc}
\hline Linguistic variables & Fuzzy numbers \\
\hline Very low & $(0.1,0.2,0.3,0.4)$ \\
Low & $(0.3,0.4,0.5,0.6)$ \\
High & $(0.5,0.6,0.7,0.8)$ \\
Very high & $(0.7,0.8,0.9,1.0)$ \\
Extremely high & $(0.9,1.0,1.0,1.0)$ \\
\hline
\end{tabular}

Table 8 presents the linguistic rating of the criteria by the experts. Based on the decision-makers responses, the information in Table 8. The information in this table shows that some of the decision-makers judgements are the same. For example, they ranked efficiency for A3 and A5 as the same. Another example is the ranking of reliability and effectiveness for A5. To process these ratings, we used the relationship between the linguistic terms and fuzzy numbers in Table 7 to generate fuzzy ratings for the measures (Table 9).

Table 8

Rating of the measures with linguistic terms

\begin{tabular}{|c|c|c|c|c|c|c|c|c|c|}
\hline & DM1 & DM2 & DM3 & DM1 & DM2 & DM3 & DM1 & DM2 & DM3 \\
\hline & \multicolumn{3}{|c|}{ A1 } & \multicolumn{3}{|c|}{$\mathrm{A} 2$} & \multicolumn{3}{|c|}{ A3 } \\
\hline $\mathrm{C} 1$ & EH & $\mathrm{EH}$ & $\mathrm{H}$ & $\mathrm{EH}$ & $\mathrm{H}$ & EH & EH & $\mathrm{EH}$ & EH \\
\hline $\mathrm{C} 2$ & EH & EH & $\mathrm{H}$ & EH & EH & $\mathrm{H}$ & EH & EH & $\mathrm{H}$ \\
\hline $\mathrm{C} 3$ & EH & $\mathrm{H}$ & $\mathrm{H}$ & $\mathrm{H}$ & $\mathrm{H}$ & $\mathrm{H}$ & EH & EH & $\mathrm{H}$ \\
\hline $\mathrm{C} 4$ & $\mathrm{H}$ & M & M & M & $\mathrm{H}$ & M & $\mathrm{H}$ & $\mathrm{M}$ & M \\
\hline C5 & EH & $\mathrm{H}$ & $\mathrm{H}$ & $\mathrm{H}$ & $\mathrm{H}$ & M & $\mathrm{H}$ & $\mathrm{H}$ & $\mathrm{H}$ \\
\hline C6 & $\mathrm{H}$ & $\mathrm{H}$ & $\mathrm{H}$ & $\mathrm{H}$ & $\mathrm{H}$ & M & $\mathrm{H}$ & $\mathrm{H}$ & $\mathrm{H}$ \\
\hline C7 & $\mathrm{H}$ & $\mathrm{H}$ & M & M & $\mathrm{H}$ & $\mathrm{L}$ & M & M & $\mathrm{L}$ \\
\hline $\mathrm{C} 8$ & $\mathrm{H}$ & M & $\mathrm{H}$ & $\mathrm{H}$ & EH & $\mathrm{H}$ & $\mathrm{H}$ & $\mathrm{H}$ & $\mathrm{H}$ \\
\hline \multirow[t]{2}{*}{ C9 } & $\mathrm{H}$ & $\mathrm{H}$ & M & EH & $\mathrm{H}$ & $\mathrm{H}$ & $\mathrm{H}$ & $\mathrm{H}$ & $\mathrm{H}$ \\
\hline & \multicolumn{3}{|c|}{ A4 } & \multicolumn{3}{|c|}{ A5 } & & & \\
\hline $\mathrm{C} 1$ & $\mathrm{H}$ & $\mathrm{H}$ & $\mathrm{EH}$ & EH & $\mathrm{EH}$ & EH & & & \\
\hline $\mathrm{C} 2$ & EH & $\mathrm{H}$ & EH & EH & EH & EH & & & \\
\hline $\mathrm{C} 3$ & EH & $\mathrm{H}$ & $\mathrm{H}$ & $\mathrm{H}$ & EH & $\mathrm{H}$ & & & \\
\hline $\mathrm{C} 4$ & $\mathrm{H}$ & $\mathrm{H}$ & M & EH & $\mathrm{H}$ & M & & & \\
\hline C5 & $\mathrm{H}$ & $\mathrm{H}$ & $\mathrm{H}$ & $\mathrm{H}$ & $\mathrm{H}$ & $\mathrm{H}$ & & & \\
\hline C6 & $\mathrm{H}$ & $\mathrm{H}$ & $\mathrm{L}$ & $\mathrm{H}$ & $\mathrm{H}$ & $\mathrm{H}$ & & & \\
\hline C7 & M & M & $\mathrm{L}$ & $\mathrm{H}$ & $\mathrm{H}$ & M & & & \\
\hline $\mathrm{C} 8$ & $\mathrm{H}$ & $\mathrm{H}$ & $\mathrm{H}$ & $\mathrm{H}$ & M & $\mathrm{H}$ & & & \\
\hline C9 & $\mathrm{H}$ & $\mathrm{H}$ & $\mathrm{H}$ & EH & $\mathrm{H}$ & $\mathrm{H}$ & & & \\
\hline
\end{tabular}


Table 9

Aggregated ratings of the measures with trapezoidal fuzzy number

\begin{tabular}{|c|c|c|c|c|c|c|c|c|c|c|c|c|}
\hline \multirow[b]{2}{*}{$\mathrm{C} 1$} & \multicolumn{4}{|c|}{ A1 } & \multicolumn{4}{|c|}{$\mathrm{A} 2$} & \multicolumn{4}{|c|}{ A3 } \\
\hline & 0.700 & 0.867 & 0.967 & 1.000 & 0.700 & 0.867 & 0.967 & 1.000 & 0.80 & 0.90 & 1.00 & 1.00 \\
\hline $\mathrm{C} 2$ & 0.700 & 0.867 & 0.967 & 1.000 & 0.700 & 0.867 & 0.967 & 1.000 & 0.70 & 0.87 & 0.97 & 1.00 \\
\hline C3 & 0.700 & 0.833 & 0.933 & 1.000 & 0.700 & 0.800 & 0.900 & 1.000 & 0.70 & 0.87 & 0.97 & 1.00 \\
\hline $\mathrm{C} 4$ & 0.500 & 0.667 & 0.767 & 1.000 & 0.500 & 0.667 & 0.767 & 1.000 & 0.50 & 0.67 & 0.77 & 1.00 \\
\hline C5 & 0.700 & 0.833 & 0.933 & 1.000 & 0.500 & 0.733 & 0.833 & 1.000 & 0.70 & 0.80 & 0.90 & 1.00 \\
\hline C6 & 0.700 & 0.800 & 0.900 & 1.000 & 0.500 & 0.733 & 0.833 & 1.000 & 0.70 & 0.80 & 0.90 & 1.00 \\
\hline C7 & 0.500 & 0.733 & 0.833 & 1.000 & 0.400 & 0.633 & 0.733 & 1.000 & 0.40 & 0.57 & 0.67 & 0.80 \\
\hline $\mathrm{C} 8$ & 0.500 & 0.733 & 0.833 & 1.000 & 0.700 & 0.800 & 0.900 & 1.000 & 0.70 & 0.83 & 0.93 & 1.00 \\
\hline \multirow[t]{2}{*}{ C9 } & 0.500 & 0.733 & 0.833 & 1.000 & 0.700 & 0.833 & 0.933 & 1.000 & 0.70 & 0.80 & 0.90 & 1.00 \\
\hline & \multicolumn{4}{|c|}{ A4 } & \multicolumn{4}{|c|}{ A5 } & & & & \\
\hline $\mathrm{C} 1$ & 0.70 & 0.83 & 0.93 & 1.00 & 0.80 & 0.90 & 1.00 & 1.00 & & & & \\
\hline $\mathrm{C} 2$ & 0.70 & 0.87 & 0.97 & 1.00 & 0.80 & 0.90 & 1.00 & 1.00 & & & & \\
\hline $\mathrm{C} 3$ & 0.70 & 0.83 & 0.93 & 1.00 & 0.70 & 0.83 & 0.93 & 1.00 & & & & \\
\hline $\mathrm{C} 4$ & 0.50 & 0.73 & 0.83 & 1.00 & 0.50 & 0.77 & 0.87 & 1.00 & & & & \\
\hline $\mathrm{C} 5$ & 0.70 & 0.80 & 0.90 & 1.00 & 0.70 & 0.80 & 0.90 & 1.00 & & & & \\
\hline C6 & 0.40 & 0.70 & 0.80 & 1.00 & 0.70 & 0.80 & 0.90 & 1.00 & & & & \\
\hline $\mathrm{C} 7$ & 0.40 & 0.57 & 0.67 & 0.80 & 0.50 & 0.73 & 0.83 & 1.00 & & & & \\
\hline $\mathrm{C} 8$ & 0.70 & 0.80 & 0.90 & 1.00 & 0.70 & 0.80 & 0.90 & 1.00 & & & & \\
\hline C9 & 0.70 & 0.80 & 0.90 & 1.00 & 0.70 & 0.83 & 0.93 & 1.00 & & & & \\
\hline
\end{tabular}

From the fuzzy values, we generated the measures' crisp values (Table 10). This study then used these values to generated the VIKOR results using a controlling coefficient of 0.5 (Liu et al., 2015). Table 11 presents the utility, regret, and VIKOR results for the measures.

Table 10

Crisp rating of the measures

\begin{tabular}{|c|c|c|c|c|c|}
\hline & A1 & $\mathrm{A} 2$ & A3 & A4 & A5 \\
\hline $\mathrm{C} 1$ & 0.986 & 0.986 & 0.991 & 0.984 & 0.991 \\
\hline $\mathrm{C} 2$ & 0.986 & 0.986 & 0.986 & 0.986 & 0.991 \\
\hline C3 & 0.984 & 0.982 & 0.986 & 0.984 & 0.984 \\
\hline $\mathrm{C} 4$ & 0.966 & 0.966 & 0.966 & 0.970 & 0.972 \\
\hline C5 & 0.984 & 0.970 & 0.982 & 0.982 & 0.982 \\
\hline C6 & 0.982 & 0.970 & 0.982 & 0.964 & 0.982 \\
\hline C7 & 0.970 & 0.960 & 0.946 & 0.946 & 0.970 \\
\hline C8 & 0.970 & 0.982 & 0.984 & 0.982 & 0.982 \\
\hline C9 & 0.971 & 0.984 & 0.982 & 0.982 & 0.984 \\
\hline
\end{tabular}

Table 11

The measures' S, R and Q values

\begin{tabular}{lccccc} 
& & & A3 & A & \\
S & A1 & A2 & 0.590 & 0.363 & 0.481 \\
R & 0.775 & 0.507 & 0.112 & 0.112 & 0.111 \\
Q & 0.500 & 0.112 & 0.222 & 0.114 \\
\hline
\end{tabular}

Fig. 3 presents the measures ranking based on the information in Table 11. This figure shows that the utility and VIKOR ranking for the alternatives are the same. It also shows that $\mathrm{A}_{1}$ is the best operational measure, while this method ranked $\mathrm{A}_{5}$ as the worst alternative. The utility and VIKOR indexes ranking for the measures is $A_{1} \succ A_{2} \succ A_{3} \succ A_{5} \succ A_{4}$. The regret ranking values for the measure is $A_{1} \succ A_{2}, A_{3}, A_{4} \succ A_{5}$.

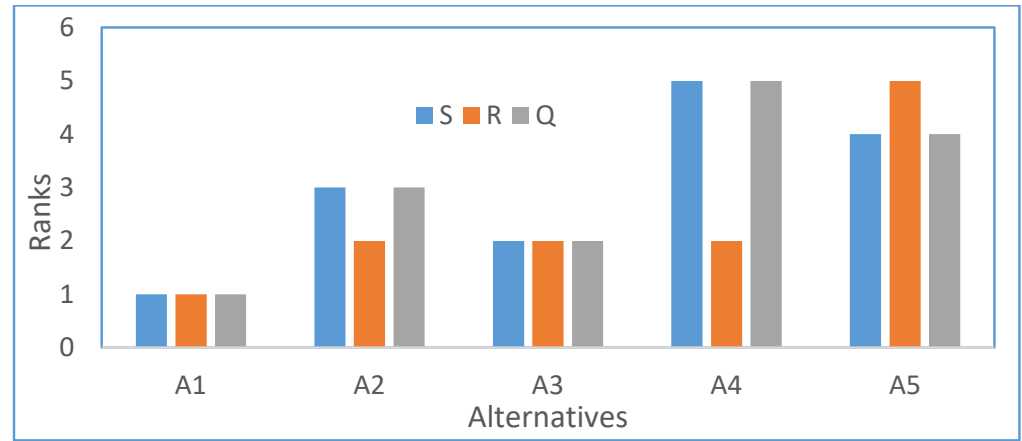

Fig. 3. The ranking of measures in ascending order by S, R and Q 
The COCOSO method implementation is based on the values in Tables 5 and 10. This study used these values to generate the measures' weighted comparability sequence (Table 12). Similarly, these values combination generated the measures' exponentially weighted comparability sequence (Table 13).

Table 12

Weighted comparability sequence for the measures

\begin{tabular}{|c|c|c|c|c|c|c|c|c|c|c|}
\hline & $\mathrm{C} 1$ & $\mathrm{C} 2$ & $\mathrm{C} 3$ & $\mathrm{C} 4$ & $\mathrm{C} 5$ & C6 & $\mathrm{C} 7$ & $\mathrm{C} 8$ & C9 & $\mathrm{G}$ \\
\hline A1 & 0.982 & 0.931 & 0.619 & 0.675 & 0.961 & 0.964 & 0.887 & 0.528 & 0.534 & 7.081 \\
\hline A2 & 0.946 & 0.878 & 0.566 & 0.592 & 0.926 & 0.946 & 0.919 & 0.592 & 0.643 & 7.008 \\
\hline A3 & 0.984 & 0.888 & 0.531 & 0.528 & 0.903 & 0.982 & 0.887 & 0.528 & 0.534 & 6.765 \\
\hline A4 & 0.982 & 0.888 & 0.531 & 0.528 & 0.903 & 0.982 & 0.890 & 0.482 & 0.569 & 6.755 \\
\hline A5 & 0.000 & 0.000 & 0.000 & 0.000 & 0.000 & 0.000 & 0.000 & 0.000 & 0.000 & 0.000 \\
\hline
\end{tabular}

Table 13

Exponentially weighted comparability sequence for the measures

\begin{tabular}{|c|c|c|c|c|c|c|c|c|c|c|}
\hline & $\mathrm{C} 1$ & $\mathrm{C} 2$ & C3 & $\mathrm{C} 4$ & $\mathrm{C} 5$ & C6 & $\mathrm{C} 7$ & $\mathrm{C} 8$ & C9 & $\mathrm{H}$ \\
\hline A1 & 0.098 & 0.097 & 0.096 & 0.083 & 0.096 & 0.094 & 0.085 & 0.085 & 0.084 & 0.818 \\
\hline $\mathrm{A} 2$ & 0.098 & 0.097 & 0.094 & 0.083 & 0.085 & 0.085 & 0.077 & 0.095 & 0.095 & 0.808 \\
\hline A3 & 0.103 & 0.097 & 0.097 & 0.083 & 0.094 & 0.094 & 0.067 & 0.097 & 0.094 & 0.826 \\
\hline A4 & 0.097 & 0.097 & 0.096 & 0.085 & 0.094 & 0.080 & 0.067 & 0.095 & 0.094 & 0.805 \\
\hline A5 & 0.103 & 0.101 & 0.096 & 0.087 & 0.094 & 0.094 & 0.085 & 0.095 & 0.095 & 0.851 \\
\hline
\end{tabular}

Analysis of the results in Tables 12 and 13 generated the COCOSO results in Table 14. These results show that $A_{1}$ is the best measure, and while it ranked $\mathrm{A}_{4}$ as the worst measure. The VIKOR and COCOSO methods ranked the same measures as best and worst measures.

\section{Table 15}

COCOSO ranking of the measures

\begin{tabular}{llc}
\hline Alternatives & K & Rank \\
\hline A1 & 0.9280 & 1 \\
A2 & 0.8636 & 4 \\
A3 & 0.8717 & 3 \\
A4 & 0.8635 & 5 \\
A5 & 0.8839 & 2 \\
\hline
\end{tabular}

\section{Conclusions}

This study has presented a framework for operational measures selection in the maritime industry. A fuzzy Shannon method was used in the framework to determine criteria importance, while fuzzy VIKOR and fuzzy COCOSO methods were used for measure selection.

This study evaluates and validates the proposed framework using real-life information obtained and analysed from Tincan port, Lagos, Nigeria. The information collected revealed that the best and worse criteria are effectiveness and congestion surcharge reduction, respectively. Five measures identified for this port, including hinterland traffic diversion, off-dock container yards. The VIKOR and fuzzy COCOSO methods ranked hinterland traffic diversion as the best measure, while they ranked fast rail shuttles worst measure for the case study's operation measures. The following contributions to knowledge have been made in this study: contribution of a design methodology for evaluating seaport operations measures and applying COCOSO method for seaport measure selection. Two areas can be considered for further studies: incorporating functional requirements into the proposed model, and applying the proposed methodology in studying other seaports.

\section{References}

Abou Kasm, O., Diabat, A., \& Cheng, T. C. E. (2019). The integrated berth allocation, quay crane assignment and scheduling problem: mathematical formulations and a case study. Annals of Operations Research, 1-27.

Agarwal, R., \& Ergun, Ö. (2008). Ship scheduling and network design for cargo routing in liner shipping. Transportation Science, 42(2), 175-196.

Aguilar-Chinea, R. M., Rodriguez, I. C., Expósito, C., Melian-Batista, B., \& Moreno-Vega, J. M. (2019). Using a decision tree algorithm to predict the robustness of a transshipment schedule. Procedia Computer Science, 149, 529-536.

Ambrosino, D., Bramardi, A., Pucciano, M., Sacone, S., \& Siri, S. (2011). Modeling and solving the train load planning problem in seaport container terminals. 2011 IEEE International Conference on Automation Science and Engineering, 208-213.

Euchi, J., Moussi, R., Ndiaye, F., \& Yassine, A. (2016). Ant colony optimisation for solving the container stacking problem: Case of le Havre (France) seaport terminal. International Journal of Applied Logistics (IJAL), 6(2), 81-101.

Fang, S., Wang, Y., Gou, B., \& Xu, Y. (2019). Toward Future Green Maritime Transportation: An Overview of Seaport 
Microgrids and All-Electric Ships. IEEE Transactions on Vehicular Technology, 69(1), 207-219.

Gong, Z., \& Liu, N. (2020). Mitigative and adaptive investments for natural disasters and labor strikes in a seaport--dry port inland logistics network. Maritime Policy \& Management, 47(1), 92-108.

Guenther, H.-O., Grunow, M., Lehmann, M., Neuhaus, U., \& Yilmaz, I. O. (2006). Simulation of transportation activities in automated seaport container terminals. Second International Intelligent Logistics System Conference.

Ighravwe, D., \& Anyaeche, C. (2019). A comparison of ARIMA and ANN techniques in predicting port productivity and berth effectiveness. International Journal of Data and Network Science, 3(1), 13-22.

Iris, Ç., Pacino, D., Ropke, S., \& Larsen, A. (2015). Integrated berth allocation and quay crane assignment problem: Set partitioning models and computational results. Transportation Research Part E: Logistics and Transportation Review, $81,75-97$.

Li, S., \& Jia, S. (2019). The seaport traffic scheduling problem: Formulations and a column-row generation algorithm. Transportation Research Part B: Methodological, 128, 158-184.

Meersman, H., de Voorde, E., \& Vanelslander, T. (2012). Port congestion and implications to maritime logistics. Maritime Logistics: Contemporary Issues, 49-68.

Mi, Y. (2016). Robust liner shipping schedule design in service networks with transshipment cut and run decisions.

Moussi, R., Euchi, J., Yassine, A., \& Ndiaye, N. F. (2015). A hybrid ant colony and simulated annealing algorithm to solve the container stacking problem at seaport terminal. International Journal of Operational Research, 24(4), $399-422$.

Na, L., \& Zhihong, J. (2009). Optimisation of continuous berth and quay crane allocation problem in seaport container terminal. 2009 Second International Conference on Intelligent Computation Technology and Automation, 3, $229-233$.

Rekik, I., \& Elkosantini, S. (2019). A multi agent system for the online container stacking in seaport terminals. Journal of Computational Science, 35, 12-24.

Rekik, I., Elkosantini, S., \& Chabchoub, H. (2017). A case based reasoning based multi-agent system for the reactive container stacking in seaport terminals. Procedia Computer Science, 108, 927-936.

Shemshadi, A., Shirazi, H., Toreihi, M., \& Tarokh, M. J. (2011). A fuzzy VIKOR method for supplier selection based on entropy measure for objective weighting. Expert Systems with Applications, 38(10), 12160-12167.

Song, L., Cherrett, T., \& Guan, W. (2012). Study on berth planning problem in a container seaport: Using an integrated programming approach. Computers \& Industrial Engineering, 62(1), 119-128.

Steenken Dirk, S. V., \& Stahlbock, R. (2004). Container terminal operation and operations research-a classification and literature review. OR Spectrum, 26(1), 3-49.

Ulutaş, A., Karakuş, C. B., \& Ayşe, T. (2020). Location selection for logistics center with fuzzy SWARA and cocoso methods. Journal of Intelligent \& Fuzzy Systems, Preprint, 1-17.

Vale, J., Ribeiro, J.A., \& Branco, M. (2017). Intellectual capital management and power mobilisation in a seaport.

Vasileva, O, \& Kiyaev, V. (2018). Monitoring and controlling the execution of the sea cargo port operation's schedule based on multi-agent technologies. CEUR Workshop Proceedings of the 2nd International Scientific and Practical Conference "Fuzzy Technologies in the Industry--FTI, 2258, 243-248.

Vasileva, Olga, \& Kiyaev, V. (2018). Generation of efficient cargo operation schedule at seaport with the use of multi-agent technologies and genetic algorithms. International Conference on Intelligent Information Technologies for Industry, 401-409.

Wang, R., Nguyen, T. T., Li, C., Jenkinson, I., Yang, Z., \& Kavakeb, S. (2019). Optimising discrete dynamic berth allocations in seaports using a Levy Flight based meta-heuristic. Swarm and Evolutionary Computation, 44, $1003-1017$.

Wang, T.-C., \& Lee, H.-D. (2009). Developing a fuzzy TOPSIS approach based on subjective weights and objective weights. Expert Systems with Applications, 36(5), 8980-8985.

Wright, S. L., Thompson, R. C., \& Galloway, T. S. (2013). The physical impacts of microplastics on marine organisms: a review. Environmental Pollution, 178, 483-492.

Yan, B., Jin, J. G., Zhu, X., Lee, D.-H., Wang, L., \& Wang, H. (2020). Integrated planning of train schedule template and container transshipment operation in seaport railway terminals. Transportation Research Part E: Logistics and Transportation Review, 142, 102061.

Yan, B., Zhu, X., Lee, D.-H., Jin, J. G., \& Wang, L. (2020). Transshipment operations optimisation of sea-rail intermodal container in seaport rail terminals. Computers \& Industrial Engineering, 141, 106296.

Yang, Z., Ng, A. K. Y., \& Wang, J. (2014). A new risk quantification approach in port facility security assessment. Transportation Research Part A: Policy and Practice, 59, 72-90.

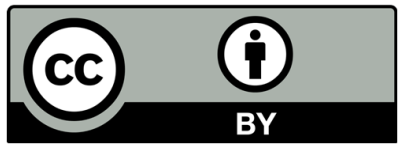

(C) 2022 by the authors; licensee Growing Science, Canada. This is an open access article distributed under the terms and conditions of the Creative Commons Attribution (CC-BY) license (http://creativecommons.org/licenses/by/4.0/). 